A CONTRIBUTION TO THE PATHOLOGY OF PNEUMOTHORAX.

BY SAMUEL WEST, M.D.,

PHYSICIAN TO THE CITY OF LONDON HOSPITAL FOR DISEASES OF THE ChEST, ASSISTANT PHYSICIAN TO THE ROYAL TREe hoSPITAL, MEDICAL REGISTRAR AND MEDICAL TUTOR AT ST. BARTHOLOMEW'S HOSPITAL.

THE material for this paper was obtained from the records of the City of London Hospital for Diseases of the Chest, Victoria-park, extending over a period of twenty-eight years, from 1856 to 1883 inclusive.

The class of cases herein to be dealt with must be first defined. A great variety of causes of pneumothorax is given by many authors, but this long list admits of much simplification, for it appears that 90 per cent. at least are due to one single cause-viz, phthisis-and the remaining 10 per cent. has to include all the other possible causes taken together. In the previous 90 per cent., cases of gangrene or acute inflammatory destruction of the lung, not phthisical, are exeluded, and as this is not an infrequent occasional cause, the percentage for the other cases becomes still further reduced; and if from these be deducted those cases in which injury either to the lung or to the parietes of the thorax have led to pneumothorax, the relative rarity of the other assigned while of those in whom the pneumothorax developed while in the hospital, 57 died, or 77 per cent. These figures indicate that the period of greatest danger or maximum mortality is in the early days of the affection, and it is the latter percentage-namely, 77-which represents probably the true mortality of the affection.

The total number of deaths from all causes during the twenty-eight years was 1499 , giving a proportion for pneumothorax of 1 in 23. As about 3 out of every 4 deatbs at the Chest Hospital are due to phthisis, this will give about 1 case of fatal pneumothorax in every 20 of phthisis ; in other words, about 5 per cent. of all cases of phthisis die from pneumothorax. This agrees with the results of Douglas Powell and Lebert, but Dr. King Chambers gives a lower percentagenamely, 3.7 ; and Weil a much higher percentage-namely, 13. Biach states that according to his statistics 1 per cent. of all cases of phthisis under treatment develop pneumothorax. I have no satisfactory statistics on this point, nor do I think a statement of this kind of any value, for a much larger proportion of all the cases of pneumothorax would naturally come under treatment than of phthisis.

The sex is specified in 98 cases-23 women and 75 men; of the women 21 died, or 87 per cent. ; of the men 45 died, or 56.3 per cent. The mortality therefore in women it would appear is higher than in men, and the numbers would also seem to show that pneumothorax is more common in men than in women, in the proportion of three to one. Weil,

TABle I. - Ages.

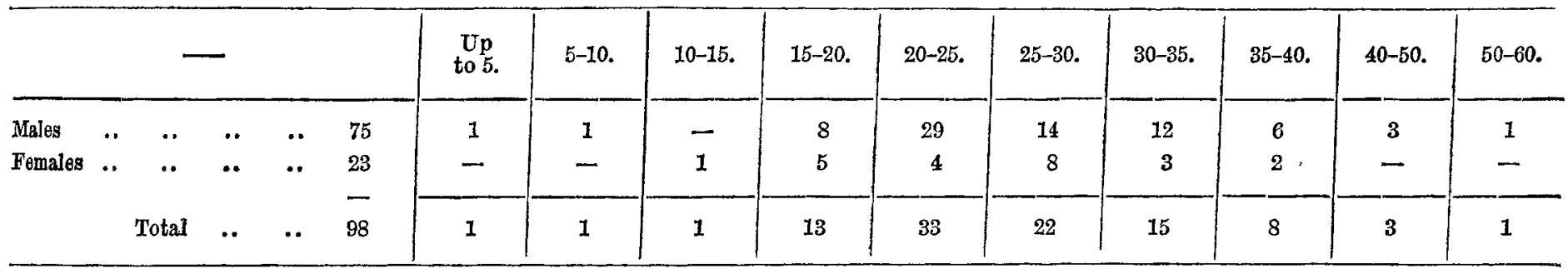

TABLE II. - Known duration.

Died during ... ...

causes becomes evident. Two or three per cent. must"embrace them all. Malignant growths or abscesses communicating on one side with an air-containing cavity, such as the csophagus, stomach, or bronchus, and on the other perforating the pleura, are pathological curiosities. Pneumothorax as a result of violent inspiratory or expiratory efforts, whether voluntary, as in whooping-cough, or artificial, as in artificial respiration, may practically be excluded from consideration here; while the real existence of the so-called non-perforative cases, where the air is supposed to have developed within a non-ruptured pleural cavity, is doubted by many. In one class only of these cases does such an event appear possible. I refer to that in which rapid putrescent decomposition has occurred in a pleuritic effusion.

Of the 101 cases referred to in this paper, only two were not distinctly due to phthisis, and even in these two phthisis could not be positively excluded, although the physical signs existing seemed to give sufficient grounds for attributing the affection rather to emphysema. This paper, then, only deals with pneumothorax in the course of phthisis. The total number of cases of pneumothorax is 101 . Of these 74 originated in the hospital, with 57 deaths, and 27 patients were admitted with pneumothorax, with 9 deaths.

Of 74 cases occurring in hospital 57 died ..... 17 left.

" 27 cases admitted with it ... $9, \ldots . . .18$,"

$\overline{101} \quad \overrightarrow{66} \quad \overline{35}$

The total mortality is 66 , or 65.4 per cent. Out of those admitted with pneumothorax only 9 died, or $33 \cdot 3$ per cent.; however, states that the proportion in the two sexes is equal.

The side affected is specified in 83 cases, and it was the right in 41 with 28 deaths, and the left in 42 with 26 deaths. So that there appears to be from the figures no special proclivity of one side to the affection. Nor does the side affected appear to modify the prognosis. Statements on this point vary. Wintrich, Regnaud, Lebert, and Louis state that the left side is twice as commonly atacked as the right, and in this Weil agrees; Laennec that the right is the favourite side; others hold, as my figures show, that both sides are equally liable.

Age.-Of the 98 cases in which the age is specified, 55 , or more than half, were between twenty-five and thirty-five; this is also the period of greatest frequency of phthisis. Cases before fifteen and after forty are very rare, only 6 out of 98 . Hughes and Weil give the same results. The youngest case in these tables was aged three years; the oldest nearly sixty.

Duration. - This is known in 39 cases and is uncertain in 37 ; of the latter, 10 occurred in the hospital, and the patients were able to leave, therefore the terminus ad quem is not fixed and 27 were admitted with it, and therefore the terminus a quo cannot be exactly ascertained. Altogether pneumothorax occurred 74 times in patients while in the hospital; and of these the duration is known exactly in 31, and approximately in 8 more ; while in the remaining 37 all that can be said is that the disease did not last less than a certain time-that is the length of their stay in the hospital. (See Table II.) 
Ten cases died on the first day, 8 after a few hours, and 2 within the first hour-i.e., twenty minutes and thirty minutes after the attack; 18 died in the first week, and 2 before the end of the fortnight. To these must be added 8 more cases in which the duration is not quite certain though it was less than fourteen days, making 29 cases that died during the first fourteen days. This is nearly 75 per cent. ; in other words, three out of every four cases are fatal within the first fortnight. Six more have died during the second fortnight; this makes 35 deaths out of 39 cases, or 90 per cent. before the end of the month. Of the remaining 10 per cent., the duration may be considerably longer, occasionally months. Weil's tables show a smaller mortality than this during the first month-20 out of 41 , or about 50 per cent. Of the cases in which the duration was uncertain, 9 were admitted with pneumothorax, and died in the hospital, so that the affection lasted, at least, as long as their stay in the hospital-viz., twenty-three days in 1 case, thirtyone days in 1 case, six weeks in 5 cases, nine weeks in 1 case, and twelve weeks in 1 case. Besides these, pneumothorax occurred 10 times in the hospital, the patients leaving or being removed at varying dates from the attack; 4 within the first week, 1 during the second, 2 during the third, I during the fourth, 1 during the ninth, and 1 after a stay of three months. Eighteen patients were admitted with pneumothorax, and left with it, and the duration was therefore at least six weeks in 8 cases, nine weeks in 1 case, ten weeks in 1 case, two months and a half in 1 case, three months in 5 cases, four months and a half in 1 case, nine months in 1 case.

Table III, is useless for statistical purposes, becanse we do not know the total number of cases. It represents the 10 per cent. residue which do not die within the first month at home, and which therefore find their way into hospital It shows, however, that, given recovery from the first shock of the attack, life may be prolonged for a considerable time.

TABLE III. - Duration uncertain.

\begin{tabular}{|c|c|c|c|c|}
\hline \multirow{2}{*}{ Totals. } & \multirow{2}{*}{$\begin{array}{l}\text { Minimum } \\
\text { duration. }\end{array}$} & \multicolumn{2}{|c|}{$\begin{array}{l}\text { Admitted with pneumothorax. } \\
\text { Terminus a quo uncertain. }\end{array}$} & \multirow{2}{*}{$\begin{array}{l}\text { Acquired pneu- } \\
\text { mothorax in } \\
\text { hospital, and } \\
\text { were dis- } \\
\text { charged. Ter- } \\
\text { minus ad quem } \\
\text { uncertain. }\end{array}$} \\
\hline & & Died. & Discharged. & \\
\hline $\begin{array}{r}5 \\
3 \\
2 \\
13 \\
4 \\
8 \\
1 \\
1 \\
1\end{array}$ & $\begin{array}{l}2 \text { weeks } \\
3 \quad \text { " } \\
4 \quad " \\
6 \\
2 \text { months } \\
3 \quad \text { " } \\
4 \frac{1}{2} \quad " \\
9 \quad "\end{array}$ & $\begin{array}{l}71 \\
1 \\
5 \\
1 \\
1 \\
-\end{array}$ & $\begin{array}{l}- \\
- \\
8 \\
2 \\
6 \\
1 \\
1\end{array}$ & $\begin{array}{l}5 \\
2 \\
1 \\
1 \\
1 \\
-\end{array}$ \\
\hline 37 & - & 9 & 18 & 10 \\
\hline
\end{tabular}

Effusion. - The presence of fluid is mentioned in the notes during life 33 times. In 4 cases its nature is not specified; and in 2 its existence was not certain, though probable. In the remaining 27 its nature was ascertained. In 9 it was found to be purulent, in 10 sero-purulent, and in 8 serous. This fact requires emphasis that the fluid was serous in about one-third of the cases, for it is contrary to the commonly accepted statement that the fluid is nearly always purulent.

Post-mortems. - The analysis of the post-mortems supplies many interesting facts. Sixty-six patients died, and in 57 the pneumothorax developed within the hospital, and was theretore not of long duration. Of these 66 there were records of 43 autopsies.

(a) Cause.-Phthisis was found to be present in all, and was therefore in all probability the cause of the affection.

(b) Perforation. - The perforation was found in 25 instances. Weil also found it in 26 cases out of 33, a rather larger proportion. The perforation was nearly always single, but two openings were found in 4 cases, four in 1 , and six in another. In 19 of the cases the duration of the disease is known. It was short in 11 ; in some only a few hours, in others a few days, but probably in all these considerably under a week. In the remaining cases the duration was longerthirteen days in 1, sixteen days in 1 , about a month in 2 , six weeks in 1 , nine weeks in 1 , eleven weeks in 1 , and five months in 1 . Hence the perforation, though as would be expected most commonly found in recent caes, does not by any means necessarily become closed even in cases of long standing.

(c) Position of the perforation.-When single it was found: (1) In the upper lobe in 10 cases, in the apex in 5 , in the middle in 1 , in the lower part in 1 , and in the posterior part in 1 ; the exact part is unspecified in 2 cases. (2) It was found in the middle lobe in 4 cases, in the centre of the lateral region in 2 , in the anterior part in 1 , and close to the sternum in 1. (3) It existed in the lower lobe in 5 cases, in the upper part in 1 , in the upper and anterior part in 1 , in the middle lateral region in 2 , and in the lateral region close to the base in 1 . When the openings were more than one they were found in the outer side of the apex in 1 (six openings), in the lower part of the upper lobe in 1 (two openings), and in both upper and lower lobe in 3 -in 1 , three openings in the lower part of the upper lobe, and one in the upper part of the lower, and in the other 2 , two openings, 1 in each of the above specified places-in the lower lobe one inch from the base in 1 (two openings). The perforation is found therefore nearly twice as often in the upper lobe, and by preference in all cases in the mid-lateral region. This appears to be also the experience of Walsh and Weil.

(d) Size of the perforation.-In the great majority of cases it was small and circular, one, two, or three lines in diameter. In one case, however, it was an irregular opening as large as a five-shilling piece. The shape is no doubt due to the retraction of the parts round the aperture, for the same shape is met with in the perforations of the intestines after ulceration.

(e) The amount of previous disease. - There is, it appears, no relation between the amount or extent of phthisical change and the occurrence of pneumothorax, though it may be stated that as a rule the liability to the affection is greatest in the rapidly-advancing cases-that is, in those where the pleural adhesions have not had time to become firm, and as a corollary of this it follows that pneumothorax does not always occur on the most affected side.

(f) The effusion, its nature and amount.-Of the 43 cases fluid was present in 20 . In 5 very short cases the pleura was unaffected in 3 , and in the remaining 2 there was slight dry pleurisy. Serum was found in 4 cases : two ounces in 2 cases of four days' duration, three ounces in 1 case lasting a few days, and a pint and a half in 1 of sixteen days duration. Sero-pus was present in 8 cases : half a pint in 1 case, and three-quarters of a pint in 1 , each of short duration; one pint in 1 of four days' duration; a pint and a half in 1 of sixty-four days' duration; copious in 4 others, the duration of 3 being four days, four weeks, and six weeks. Pus was found in 8 cases also: a little in 1 case of a few hours' duration, four ounces in 1 of tleven weeks, fifteen ounces in 1 lasting four months, one pint in 2 cases of one month and uncertain duration, two pints in 1 case of four days and uncertain duration, copious in 2 cases of five months and uncertain duration. The effusion, therefore, is commonly serous in the early stage. It may even remain serous for a considerable time; but in many cases of long duration it ultimately becomes sero-purulent or purulent, though it may be purulent from the commencement, and even reach a considerable amount in a few days-e.g., two pints in four days. The quantity varies considerably. As a rule it becomes larger the longer the affection laste, and is then, as has been stated, usually purulent; but it may become copious in a short timee.g., in 2 cases of only four days' duration the quantity amounted to two pints of pus in one, and was described as copious (sero-purulent) in the other. The amount, how. ever, may, even in a long case, continue small ; in one case after eleven weeks it reached only two ounces, and in another of four months' duration only fifteen ounces, and that although it was in both cases pus. The post-mortem examinations therefore confirm the previous statement that serous effusion is common-indeed, that the serous and sero. purulent together are even mere common than the purulent effusions.

The points of this paper may be summarised as follows. 1. It deals only with pneumothorax in the course of phthisis, to which disease at least 90 per cent. of all the cases is attributed. 2. About 5 per cent. of all deaths from phthisis are the result of pneumothorax. 3. Of the cases of pneumothorax, about 75 per cent. die within the first fourteen days, and about 90 per cent. before the end of the first montb, though the duration of life of the re- 
maining 10 per cent. may be considerable. 4. The period of greatest frequency coincides with the period of greatest mortality from phthisis, and lies between the ages of twenty-five and thirty-five. 5. Pneumothorax is very rare before the age of tifteen or after forty. 6 . It is commoner in men than in women, but the mortality is greater in women. 7. One side of the chest is not more prone to be attacked than the other, nor does the side attacked modify the prognosis. 8. Effusion commonly occurs, though not necessarily. It is not necessarily purulent; in fact serous, sero-purulent, and purulent effusions are of about equal frequency, though in cases of long duration an effusion which was serous to begin with often becomes purulent. 9. The chances of effusion being present, and of that effusion being copious and probably also purulent, increase with the duration of the case ; but effusion may be absent throughout, or be scanty in old cases and copious in recent cases, or whether large or small remain serous throughout or be purulent from the commencement. 10. The perforation is found in about two.thirds of the cases, and may be discovered even in cases of long standing. It is usually single, but may be multiple, It is generally circular in shape. Its size is commonly small. two or three lines, but occasionally it is large, even an inch or more in diameter. Its favourite position is in the upper lobe, where it occurs nearly twice as frequently as elsewhere and in the mid-lateral region. 11. There is, lastly, no relation between the amount of lung disease and the occurrence of pneumothorax.

The statiatics of pneumothorax are not numerous. The results of the present inquiry confirm those of previous writers in most respects, and attention has been drawn en passant to the chief points of difference. I have dealt almost exclusively with the pathological phenomena of pneumothorax, desiring to reserve for a further communication the more strictly clinical aspect of this affection, which does not so readily adapt itself to a statistical inquiry.

\section{STRATHPEFFER AS A HEALTH RESORT.}

BY BERKELEY HILL, F.R.C.S. ENG., SURGEON TO UNIVERSITY COLLEGE HOSPITAL.

LAST vacation circumstances led me to stay at Strathpeffer, in Ross-shire, where is a sulphur spring of great power, of high repute in the north, and now attracting visitors from the south also in increasing numbers. The great natural capacity of the locality and the high value of its mineral waters need only moderate development to make the place a favourite resort for the gouty or rheumatic invalid. Nearly the whole valley is the property of the Duchess of Sutherland, who takes considerable interest in the prosperity of the spa. In order to make it more accessible next season than heretofore, this lady is having a short branch line carried into the centre of the village from the Dingwall and Skye Railway, by which the valley is approached from Inverness. This will greatly lessen the fatigue of the journey from the south at its further end. From London, Strathpeffer is reached in from sixteen to eighteen hours, with two changes of carriage, at Perth and at Inverness for travellers in small parties, though if a whole saloon be taken at Euston the journey may be made with out change of carriage. The valley, which runs westward from Dingwall for four miles before the spa is reached, gradually ascends and narrows until at the site of the village the houses are pitched at about 200 feet above the sea level on slopes and terraces which gradually rise to respectable hills along the northern side, where they culminate in Ben Wyvis, 3400 feet above the sea. The northern side of the valley is of old red sandstone and slaty schist; the southern, formed by two most picturesque crests-the Catshack and Knockfarrel,--is composed of conglomerate. The valley bottom is of detritus and alluvium, and consequently most fertile. Being well sheltered from the winds, for the rising peaks of the Ross-shire mountains receive most of the rain-clouds which drench Skye with rain and mist, the climate is by no means a highland one. The atmosphere is drier and more equable than in many parts of Scotland; the rainfall being $25 \cdot 30$ inches, and the number of rainy days les s than in London. Heavy crops of wheat, large walnut and fig trees growing and ripening their fruit in the open air, testify not merely to the mildness of the winters, but to the plentiful sunlight of the summer months in this northern corner of Scotland I was assured that during the last few winters when the High. land and other Scotch railways had been blocked for weeks by snow, the road through this valley had been open to Skye without interruption. The varied geological formation of the district affords great variety of landscape. The hills are topped with purple heather and clothed below with pine or birch, and the valleys are set with little lakes or dotted with large oaks or elms. There is a mixture of Highland and English scenery of never-tiring freshness. In the bottom, streams tumble over rocks, down very respectable waterfalls, up which the salmon leap perseveringly on their way to their spawning grounds. Thus strathpeffer is rich in temptivg walks and pleasant excursions; but these, alas ! are impossible for those whose power of walking is almost lost, and of such cripples not a few come to drink the waters. A small outlay in easy-winding paths and drives would render the lower hills, with their delightful views and exhilarating breezes, accessible to the infirm, who now suffer somewhat in the mild, relaxing air of the valley bottom. For those who do not need to swallow every day the sulphur water, excursions occupying two or three days may be made to Skye, Loch Maree, Gairloch, and other districts, where some of the finest scenery in Scotland is situated. The copious sulphur springs are some of the strongest in the world. They contain more than double the amount if sulphuretted hydrogen held in solution by the Harrogate waters; while those of Aix-la-Chapelle, being hot, contain none, or next to none. Of uncombined sulphur dissolved or suspended in the water, Strathpeffer is, again, richer than either Harrogate or Aix-la-Chapelle. The salts, chiefly lime, soda, and magnesia, are scanty, and are less in the Strathpeffer than in the Harrogate waters; hence they are not aperient, though highly diuretic, and in this quality excel the waters of continental springs. The quantity to be druok varies with the nature of the case. Dr. Manson, the resident physician of Strathpeffer, prescribes them to be taken twice daily, between 6.30 and $8 \mathrm{~A} . \mathrm{M}$. and from noon to 1 o'clock - that is, an hour before breakfast and dinner or luncheon-and from one to two or three pints to be drunk each time. The sulphur water is also used, artificially heated, for bathing and for inhalations. The length of a course extends from three to six or eight weeiss. Some very remarkable cures of bepatic enlargement, rheumatism, gout, and chronic cystitis came under my notice at Stratbpeffer. The waters, doubtless, have the main influence in working a cure; but it must be conceded that a part of the success is due to the pleasant surroundings of the spa and sociable behaviour of the visitore, who fall in readily with the distractions of the place in the shape of balls, concerts, \&c., held in the large pavilion erected last summer close to the pump-room. The appliances for batbing are not so much developed as might be. There is a tolerable bathing house connected with the pump-room, but nothing is attempted beyond hot sitz-and shower-baths, The addition of vapour-, needle-, douche-, mud-, mercurial-, and Turkishbaths, served by good rubbers and shampooers, would materially increase the curative means at the disposal of the physician, and enable him to deal with a large class of affections of the joints, skin, and digestion, for the cure of which the climate of Strathpeffer is very favourable. By the possession of a very remarkable and almost unique chalybeate spring. in addition to its bracing air and clear atmosphere, Strathpeffer is peculiarly suited for the cure of anzemia and other affections for which iron is useful. The full value of this spring has been only lately recognised. For some years past a ferruginous water has been brought from its source to the pump-room, being first collected in a well for subsidence and filtered before being led in pipes to the pump. room. Under this treatment the water was a chalybeate of no great value, and much inferior to the spring at Well-walk, Hampstead, once famous, though now little thought of. During my stay at Stratbpeffer it occurred to Dr. Manson to examine the source of the iron spring, and finding it there to be very different from its condition in the pump-room, he turned it at once into the pipes. It now reaches the pump-room in the state in which it escapes from the rocks, and is completely changed. The water is now so highly charged with carbonic acid that as it fills the glass it is milky white from the release of the gas in minute bubbles. In this state it is most exhllarating and of an agreeable subacid flavour. The iron, instead of being in great part precipitated as oxide, is retained in solution as carbonate by excess of carbonic acid, and is of course of high value as a tonic. This water closely 